\title{
Toward a high resolution 2-DE profile of the normal human liver proteome using ultra-zoom gels
}

\author{
MI Wei ${ }^{1,2 \dagger}$, LIU Xin $^{2 \dagger}$, JIA Wei $^{2}$, LI Lei ${ }^{2}$, CAI Yun ${ }^{2}$, YING WanTao $^{2 *} \&$ QIAN XiaoHong ${ }^{2 *}$ \\ ${ }^{1}$ Department of Biology, Energy and Environment, National Institute of Metrology, Beijing 100013, China; \\ ${ }^{2}$ State Key Laboratory of Proteomics, Beijing Proteome Research Center, Beijing Institute of \\ Radiation Medicine, Beijing 102206, China
}

Received May 27, 2010; accepted June 18, 2010

\begin{abstract}
The human liver is the largest organ in the body and has many important physiological functions. A global analysis of human liver proteins is essential for a better understanding of the molecular basis of the normal functions of the liver and of its diseases. As part of the Human Liver Proteome Project (HLPP), the goal of the present study was to visualize and detect as many proteins as possible in normal human livers using two-dimensional gel electrophoresis (2-DE). We have constructed a reference map of the proteins of human normal liver that can be used for the comprehensive analysis of the human liver proteome and other related research. To improve the resolution and enhance the detection of low abundance proteins, we developed and optimized narrow $\mathrm{pH}$ range ultra-zoom 2-DE gels. High resolution patterns of human liver in $\mathrm{pH}$ gradients 4.5-5.5, 5-6, 5.5-6.7, 6-9 and 6-11 are presented. To improve the poor resolution in the alkaline $\mathrm{pH}$ range of 2-DE gels, we optimized the isoelectric focusing protocol by including sample application using cup loading at the anode and incorporating $1.2 \%$ hydroxyethyl disulfide, 15\% 2-propanol and 5\% glycerol in the rehydration buffer. Using the optimized protocol, we obtained reproducibly better resolution in both analytical and preparative 2-DE gels. Compared with the 2386 and 1878 protein spots resolved in the wide range 3-10 and 4-7 pH gradients respectively, we obtained 5481 protein spots from the multiple (overlapping) narrow $\mathrm{pH}$ range ultra-zoom gels in the range of $\mathrm{pH} 4.5-9$. The visualized reference map of normal human liver proteins presented in this paper will be valuable for comparative proteomic research of the liver proteome.
\end{abstract}

human liver proteome, two-dimensional gel electrophoresis, ultra-zoom gel, mass spectrometry

Citation: $\quad$ Mi W, Liu X, Jia W, et al. Toward a high resolution 2-DE profile of the normal human liver proteome using ultra-zoom gels. Sci China Life Sci, 2011, 54: 25-33, doi: 10.1007/s11427-010-4120-3

The liver is the largest organ and the most complicated chemical plant in the human body. It is involved in over 500 kinds of biochemical reactions, possesses over 1000 functions, and plays various critical roles in human metabolism, hematopoiesis, and the transfer and supply of energy. Diseases of the liver are widespread in China. According to World Health Organization (WHO) statistics, 350 million people in the world are chronic viral hepatitis B carriers and about half of them (150 million) are in China [1]. To address this serious health issue and explore its pathological

\footnotetext{
$\uparrow$ Contributed equally to this work

*Corresponding author (email: yingwtll@yahoo.com.cn; qianxh1@yahoo.com.cn)
}

mechanisms, a comprehensive study of the human liver proteins that control these complicated biochemical reactions is essential. The Human Liver Proteome Project (HLPP) was launched as the first initiative focusing on the proteomic analysis of the human liver. It aims to thoroughly study the liver proteins and explore their significance in human physiology and pathology. One of the objectives of HLPP is to construct the protein expression profile of the normal human liver by separating, detecting and identifying as many proteins as possible [2].

To separate complex protein mixtures, two-dimensional gel electrophoresis (2-DE) combined with protein identification by mass spectrometry (MS) is currently the work- 
horse for proteomics [3,4], although some promising new technologies (e.g., multidimensional protein identification technology, MudPIT) are emerging and have been applied recently [5]. 2-DE separates proteins according to their isoelectric point $(\mathrm{pI})$ and molecular mass $\left(M_{\mathrm{r}}\right)$, effectively reflecting changes in protein expression levels, isoforms and post-translational modifications [6,7]. In many reports, the immobilized $\mathrm{pH}$ gradients (IPGs) applied in 2-DE are over wide $\mathrm{pH}$ ranges (e.g., $\mathrm{pH} 3-10$ or $\mathrm{pH} 4-7$ ) which limit, to 1000-3000, the number of protein spots that can be visualized on a standard 2-D gel. To visualize more protein spots and detect more of the low-abundant proteins, multiple (overlapping) narrow $\mathrm{pH}$ range IPGs have been used, allowing better separation in the first dimension of 2-DE $[8,9]$. Narrow-overlapping $\mathrm{pH}$ gradients, $1-3 \mathrm{pH}$ units wide, referred to as ultra-zoom gels, provide increased resolution $(\Delta \mathrm{pI}=0.001)$ [10]. Wildgruber et al. [8] have demonstrated the improved separation and visualization of the Saccharomyces cerevisiae proteome using ultra-zoom gels. They found that by combining IPGs 4-5, 4.5-5.5, 5-6, 5.5-6.7, and 6-9 and excluding overlaps, three times more protein spots were detected than when a wide-range IPG 3-10 was used.

In the present study, we utilized ultra-zoom gels to analyze normal human liver proteins. We used IPGs 4.5-5.5, 5-6, 5.5-6.7, 6-9 and 6-11 to obtain high resolution 2-DE gels, and presented a composite 2-DE map of normal human liver from $\mathrm{pH} 4.5-9$ with 5481 protein spots. To address the poor resolution in the alkaline $\mathrm{pH}$ range $(\mathrm{pH}$ 6-9 and $\mathrm{pH}$ 6-11) of the 2-DE gels, we optimized the rehydration buffer, sample application, and the isoelectric focusing protocol to obtain better resolved 2-DE gels.

\section{Materials and methods}

\subsection{Sample preparation}

Normal human liver tissue was obtained from the CNHLPP (China Human Liver Proteome Project) Sampling Committee. The use of these samples for proteome analysis was approved by the cancer institution's local ethical committee. Extensive clinical and laboratory data were collected from each volunteer after obtaining informed consent. To reduce individual variations, 10 individual samples were pooled to create a uniform sample. Briefly, fresh liver samples were cleaned with ice-cold PBS at $4{ }^{\circ} \mathrm{C}$ soon after they were received. The samples were cut into pieces, weighed and preserved in liquid nitrogen until they were used. When required, $0.5 \mathrm{~g}$ frozen liver powder was homogenized in $5 \mathrm{~mL}$ lysis buffer. Two different lysis buffers were used: Buffer A contained $7 \mathrm{~mol} \mathrm{~L}^{-1}$ urea, $2 \mathrm{~mol} \mathrm{~L}^{-1}$ thiourea, 4\% CHAPS, $1 \%$ DTT, $1 \mathrm{mmol} \mathrm{L}{ }^{-1}$ PMSF, $0.2 \mathrm{mmol} \mathrm{L}{ }^{-1} \mathrm{Na}_{2} \mathrm{VO}_{3}$ and 1 mmol L ${ }^{-1} \mathrm{NaF}$; buffer B contained $9.5 \mathrm{~mol} \mathrm{~L}^{-1}$ urea, $2 \%$ CHAPS, $0.5 \%$ SDS, $1 \%$ DTT, $1 \mathrm{mmol} \mathrm{L}^{-1}$ protease inhibi- tor cocktail, $0.2 \mathrm{mmol} \mathrm{L} \mathrm{L}^{-1} \mathrm{Na}_{2} \mathrm{VO}_{3}$ and $1 \mathrm{mmol} \mathrm{L}{ }^{-1} \mathrm{NaF}$. The homogenate was lysed by sonication and the mixture was incubated at room temperature for $30 \mathrm{~min}$. After $1 \mathrm{~h}$ of centrifugation at $25000 \times g$, a clear protein extract was obtained. The protein concentration was determined using the RC-DC Protein Assay (Bio-Rad) and the protein extracts were stored at $-80^{\circ} \mathrm{C}$. The protein extracts were purified by acetone precipitation. The protein solution was mixed with cold acetone in the ratio $1: 3(\mathrm{v} / \mathrm{v})$, and the mixture was stored at $-20^{\circ} \mathrm{C}$ overnight or longer. After 15 min of centrifugation at $21000 \times g$, the supernatant was discarded and the protein pellet was dried in Speedvac. The pellet was redissolved in 2-DE sample buffer containing $7 \mathrm{~mol} \mathrm{~L}^{-1}$ urea, $2 \mathrm{~mol} \mathrm{~L}^{-1}$ thiourea, and $4 \% \mathrm{CHAPS}$. Any residue was removed by centrifugation for $30 \mathrm{~min}$ at $21000 \times g$.

\subsection{Two-dimensional electrophoresis and image analy- sis}

Isoelectric focusing (IEF) was performed using Ettan IPGphor (Amersham Biosciences, San Francisco, CA, USA). $18 \mathrm{~cm}$ IPG strips and IPG buffers $(\mathrm{pH} 4.5-5.5, \mathrm{pH}$ 5-6, pH 5.5-6.7, pH 6-9, pH 3-10, and pH 4-7) were purchased from Amersham Biosciences. Samples were applied either by rehydration loading or by cup loading according to the $\mathrm{pH}$ range of the IPG strips. The IPG strips, except for those at $\mathrm{pH}$ 6-9, were loaded by in-gel rehydration for $12 \mathrm{~h}$ in a solution containing $8 \mathrm{~mol} \mathrm{~L}^{-1}$ urea, $2 \%$ CHAPS, $0.5 \%$ DTT and $0.5 \%$ IPG buffer (a different IPG buffer for the different $\mathrm{pH}$ ranges) and focused according to the standard protocol [3]. The IPG strips at $\mathrm{pH}$ 6-9 were rehydrated overnight at $20^{\circ} \mathrm{C}$ in $340 \mu \mathrm{L}$ rehydration buffer $\left(7 \mathrm{~mol} \mathrm{~L}{ }^{-1}\right.$ urea, $2 \mathrm{~mol} \mathrm{~L}^{-1}$ thiourea, 4\% CHAPS, 5\% glycerol, $15 \%$ 2-propanol, 1.2\% DeStreak reagent, 2.5\% DTT, 2\% IPG buffer at pH 6-11). For each IPG strip, samples in a volume less than $100 \mu \mathrm{L}$ were applied by cup loading at the anodic end and the IEF protocol described in Table 1 was used.

Following IEF separation, the strips were equilibrated for $15 \mathrm{~min}$ in $10 \mathrm{~mL}$ equilibration buffer 1 (1\% DTT, $6 \mathrm{~mol} \mathrm{~L}^{-1}$ urea, $30 \%$ glycerol, $50 \mathrm{mmol} \mathrm{L}{ }^{-1}$ Tris- $\mathrm{HCl}$ at $\left.\mathrm{pH} 8.8\right)$ and then for $15 \mathrm{~min}$ in $10 \mathrm{~mL}$ equilibration buffer $2(2.5 \%$ iodoacetamide, $6 \mathrm{~mol} \mathrm{~L}^{-1}$ urea, $30 \%$ glycerol, $50 \mathrm{mmol} \mathrm{L}^{-1}$ Tris- $\mathrm{HCl}$ at $\mathrm{pH} 8.8$ ). For the second dimension, strips were applied to $12.5 \%$ SDS-PAGE using PROTEAN II xi cell

Table 1 Optimized IEF protocol for $\mathrm{pH}$ 6-9 and pH 6-11 IPG strips

\begin{tabular}{ccccc}
\hline Step & Voltage (V) & $\begin{array}{c}\text { Volt-hours } \\
(\text { Vh })\end{array}$ & $\begin{array}{c}\text { Step duration } \\
(\mathrm{h}: \min )\end{array}$ & Gradient type \\
\hline 1 & 0 & 0 & $12: 00$ & \\
2 & 200 & 30 & $0: 10$ & Step-n-hold \\
3 & 600 & 200 & $0: 20$ & Step-n-hold \\
4 & 4000 & 14000 & $3: 30$ & $\begin{array}{c}\text { gradient } \\
\text { depends on sam- } \\
\text { ple volumn }\end{array}$ \\
5 & 8000 & $>64000$ & $>8: 00$ & \\
\hline
\end{tabular}


system (Bio-Rad, CA, USA). Electrophoresis was performed with constant current at $10 \mathrm{~mA} / \mathrm{gel}$ for $15 \mathrm{~min}$ and then at $25 \mathrm{~mA} / \mathrm{gel}$ until the tracking dye was about $1 \mathrm{~cm}$ from the end of the gel.

For analysis, the 2-DE gels were stained with silver according to the manufacture's recommendation. Briefly, the gels were fixed in $40 \%$ ethanol and $10 \%$ acetic acid for 30 min. Sensitizing was carried out for $30 \mathrm{~min}$ in $30 \%$ ethanol, $5 \%(\mathrm{w} / \mathrm{v})$ sodium thiosulfate, $6.8 \%(\mathrm{w} / \mathrm{v})$ sodium acetate and $25 \%(\mathrm{w} / \mathrm{v})$ glutaraldehyde. The gels were then washed in water three times, for $5 \mathrm{~min}$ each time, and incubated in $2.5 \%(\mathrm{w} / \mathrm{v})$ silver nitrate for $20 \mathrm{~min}$. After this, the gels were washed twice in water, for $1 \mathrm{~min}$ each time, and developed with $3 \%(\mathrm{w} / \mathrm{v}) \mathrm{Na}_{2} \mathrm{CO}_{3}$ and $0.025 \%$ (v/v) formaldehyde until the desired contrast was reached. The reaction was stopped using $1.5 \%(\mathrm{w} / \mathrm{v})$ EDTA-Na $\mathrm{N}_{2}$. The preparative 2-DE gels, loaded with $1 \mathrm{mg}$ protein on each gel, were stained with colloidal Coomassie blue as described by Candiano et al. [11]. Briefly, 2-DE gels were fixed in $10 \%$ methanol, $7 \%$ acetic acid for $30 \mathrm{~min}$, and stained overnight in the working solution containing $0.12 \%$ Coomassie Blue G-250 (Amresco, USA), 10\% ammonium sulfate, 10\% phosphoric acid, and $20 \%$ methanol. The gels were destained with $10 \%$ methanol.

The gels were scanned with ImageScanner (Amersham Biosciences). Spot detection, background subtraction and quantification of the images were performed using the software of ImageMaster 2D evolution (Amersham Biosciences).

\subsection{Protein spot-cutting and in-gel tryptic digestion}

Protein spots were selected through image analysis with ImageMaster 2D software (Amersham Biosciences), excised with an Ettan Spot Picker (Amersham Biosciences) as 1-mm gel plugs, and deposited in 96-well microplates. The liquid was removed and the gel plugs were destained with a $1: 1(\mathrm{v} / \mathrm{v})$ solution of $50 \mathrm{mmol} \mathrm{L}^{-1}$ ammonium bicarbonate and ACN. Then the plugs were dehydrated with ACN at room temperature. After $\mathrm{ACN}$ removal, the gel plugs were rehydrated at $4^{\circ} \mathrm{C}$ for $40 \mathrm{~min}$ in $10 \mu \mathrm{L}$ trypsin solution (10 ng $\mu \mathrm{L}^{-1}$ modified sequencing grade modified trypsin) and incubated overnight at $37^{\circ} \mathrm{C}$. The plugs were extracted twice, once by incubating for an hour at $40^{\circ} \mathrm{C}$ with $25 \mu \mathrm{L}$ of $5 \%$ TFA solution and once more by incubating for $1 \mathrm{~h}$ at $30^{\circ} \mathrm{C}$ with $25 \mu \mathrm{L}$ of $2.5 \% \mathrm{TFA} / 50 \% \mathrm{ACN}$ solution. The extracts were then combined and concentrated.

\subsection{Protein identification by MALDI-TOF-TOF MS}

The tryptic peptides from 2-DE gels were analyzed using an Applied Biosystems 4700 Proteomics Analyzer instrument (Applied Biosystems, Framingham, MA, USA). The eluted peptides in $0.1 \% \mathrm{TFA} / 50 \% \mathrm{ACN}$ solution were applied onto the MALDI target plate. After the targets were air-dried, 0.5 $\mu \mathrm{L}$ saturated $\alpha$-cyano-4-hydroxycinnamic acid (CHCA) in $0.1 \% \mathrm{TFA} / 50 \% \mathrm{ACN}$ was added to the targets. The mass spectrometer was externally calibrated with a standard peptide mixture of angiotensin I, Glu-fibrinopeptide B, ACTH (1-17), АCTH (18-39), ACTH (7-38) and des-Agr-bradykinin. For the tandem mass spectrometry (MS/MS) experiments, the instrument was externally calibrated with fragments of Glu-fibrinopeptide. After the external calibration, internal calibration was also performed using two autolysis peaks of trypsin $(\mathrm{m} / \mathrm{z}, 842.51,2211.11)$ during the MS spectra collection. All MS experiments were carried out in the positive reflection mode and all MS/MS experiments were performed in the positive $1 \mathrm{keV}$ MS/MS reflection mode under "metastable off suppressor" conditions. Based on the data-dependent mode, the top eight intensive precursors with a signal to noise ratio of more than 20 were selected from the MS spectra. During MS data acquisition, 1500 shots composed of 12 subspectra each (subspectra accumulated from 125 laser shots each) were collected and, for MS/MS data acquisition, 2500 shots composed of 25 subspectra each (subspectra accumulated from 100 laser shots each) were collected. The parent ion selection window was set to $0.02 \%$ resolution.

\subsection{Data analysis}

GPS 2.0 software (based on Mascot) was installed on the 4700 Proteomics Analyzer instrument. Spectral data were searched against the international protein index (IPI, version 3.07) (an inverse database used for evaluating the false positive results was included). Parameters for the database search were as follows: Allowed variable modifications were carbamidomethyl for cysteines and oxidation for methionines, peptide mass tolerance was $0.01 \%$, fragment mass tolerance was $0.6 \mathrm{Da}$, and the maximum missed tolerance was one. For peak filtering we used a minimum $S / N$ ratio of 20, peak density filter of 30 peaks per $200 \mathrm{Da}$, and cluster area filter with the maximum number of peaks 100 . The criterion for protein identification was that the protein score was significant $(P<0.05)$ and higher than 60 . All the MS spectra were manually inspected to verify the validity of the results. The hydrophobicity, subcellular location and function of the identified proteins were elucidated by gene ontology analysis using the GOfact on the website (http:// www.hupo.org.cn/gofact).

\section{Results and discussion}

\subsection{Liver protein extraction under different lysis buff- ers}

We compared two kinds of protein extract buffer for protein extraction. Using the same weight of liver powder and the same extraction protocol, lysis buffer A gave a protein concentration of $12 \mu \mathrm{g} \mu \mathrm{L}^{-1}$, while lysis buffer B gave $15.5 \mu \mathrm{g}$ 
$\mu \mathrm{L}^{-1}$. We performed comparative 2-DE using the different protein solutions with the same quantity of sample loading and, by image analysis, found many more protein spots on the gels of the proteins extracted using buffer B than on gels of those extracted using buffer A (data not shown). Clearly, lysis buffer B has better extract efficiency than lysis buffer A. The addition of SDS to lysis buffer B is an important reason for this because SDS is one of the most efficient surfactants and has been recommended for protein solubilization [12,13]. However, SDS interferes with IEF producing horizontal streaks in 2-D gels and the final concentration of SDS in IEF sample buffers is recommended to be below $0.25 \%$ [14]. In our study, sample proteins were treated with acetone, and then SDS including salt was removed by acetone precipitation. The sample treated with acetone was so compatible with 2-DE that it was used for all analytical and preparative 2-DE experiments in this work.

\subsection{High resolution 2-DE analysis of the normal hu- man liver proteome}

Analytical silver-stained gels loaded with $100 \mu \mathrm{g}$ of human liver proteins yielded 2386 detectable spots using a broad range IPG 3-10 for the IEF step (Figure 1A), while using IPG 4-7 only 1878 protein spots were detectable (Figure 1B). To achieve optimal resolution and visualize more protein spots on the gels, we used multiple narrow overlapping IPGs (ultra-zoom gel) to separate human liver proteins. Figure 2 shows the analytical gels with IPG 4.5-5.5 (Figure 2A), IPG 5-6 (Figure 2B), IPG 5.5-6.7 (Figure 2C), and IPG 6-9 (Figure 2D). We analyzed the images of adjacent narrow $\mathrm{pH}$ range to identify overlapping regions and overlapping proteins. The narrow-range IPG 2-D gel images were visually concatenated by overlaying overlapping regions to produce a combined reference map for the human liver proteome. Regions of continuity between two IPG ranges were inferred by comparing them with correspond-

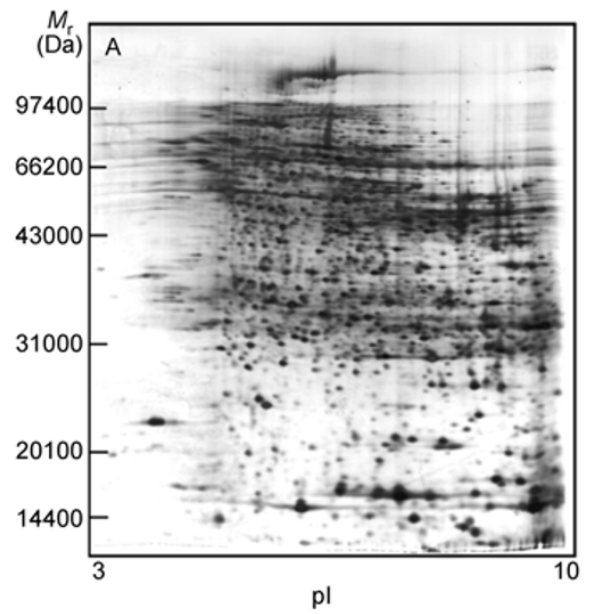

ing regions on $\mathrm{pH}$ 3-10 and $\mathrm{pH}$ 4-7 IPG gel images. The overlapping regions and the overlapping proteins are indicated in Figure 2. On the composite gel constructed by combining the IPG 4.5-5.5, 5-6, 5.5-6.7, and 6-9 gel images and excluding overlaps so that every protein spot was counted only once, we were able to detect 5481 protein spots. Thus, in comparison to the 2-DE map with IPGs 3-10 and 4-7, by using the composite map, we successfully increased the number of spots that were observed. The strategy of using narrow IPGs has been successfully applied for the identification of yeast and HEK cell proteins $[8,15]$.

\subsection{Optimization of the 2-DE protein separation in the alkaline range}

Existing 2-DE technology is challenged by difficulties in resolving hydrophobic proteins, alkaline proteins and low abundance proteins [16]. About $40 \%$ of the proteins in the human proteome may have pIs higher than 8 [17]. Therefore, for the construction of a comprehensive proteome reference 2-DE map, it is necessary to optimize protein separation in the alkaline range.

In this study, we used in-gel rehydration sample application in IEF to analyze neutral and acidic proteins in $\mathrm{pH}$ ranges 3-10, 4.5-5.5 and so on. Sample application by in-gel rehydration, commonly used for wide $\mathrm{pH}$ range IPGs [18], was effective for acidic $\mathrm{pH}$ range IPGs (Figure 2A and $\mathrm{B})$. In-gel rehydration has the benefit of accommodating heavy loading and resolving high molecular weight proteins [19]. However, in-gel rehydration is not suitable for resolving alkaline proteins, and to significantly improve the 2-D gel resolution, cup-loading at the anode end of alkaline IPG strip and the use of high voltages (final settings up to 8000 $\mathrm{V})$ have been strongly recommended [20].

It has also been reported that the addition of 2-isopropanol and glycerol to the rehydration buffer improves the focusing of proteins in the alkaline IPG strips by reducing

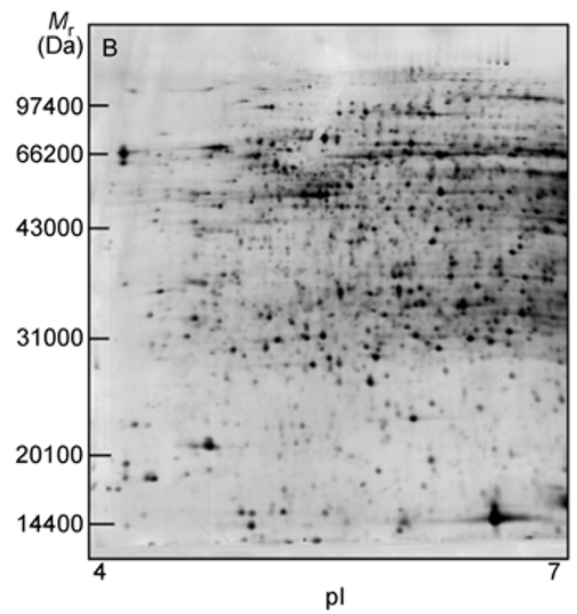

Figure 1 Analytical silver-stained gels with $100 \mu \mathrm{g}$ human liver protein. A, IPG pH 3-10; B, IPG pH 4-7. 

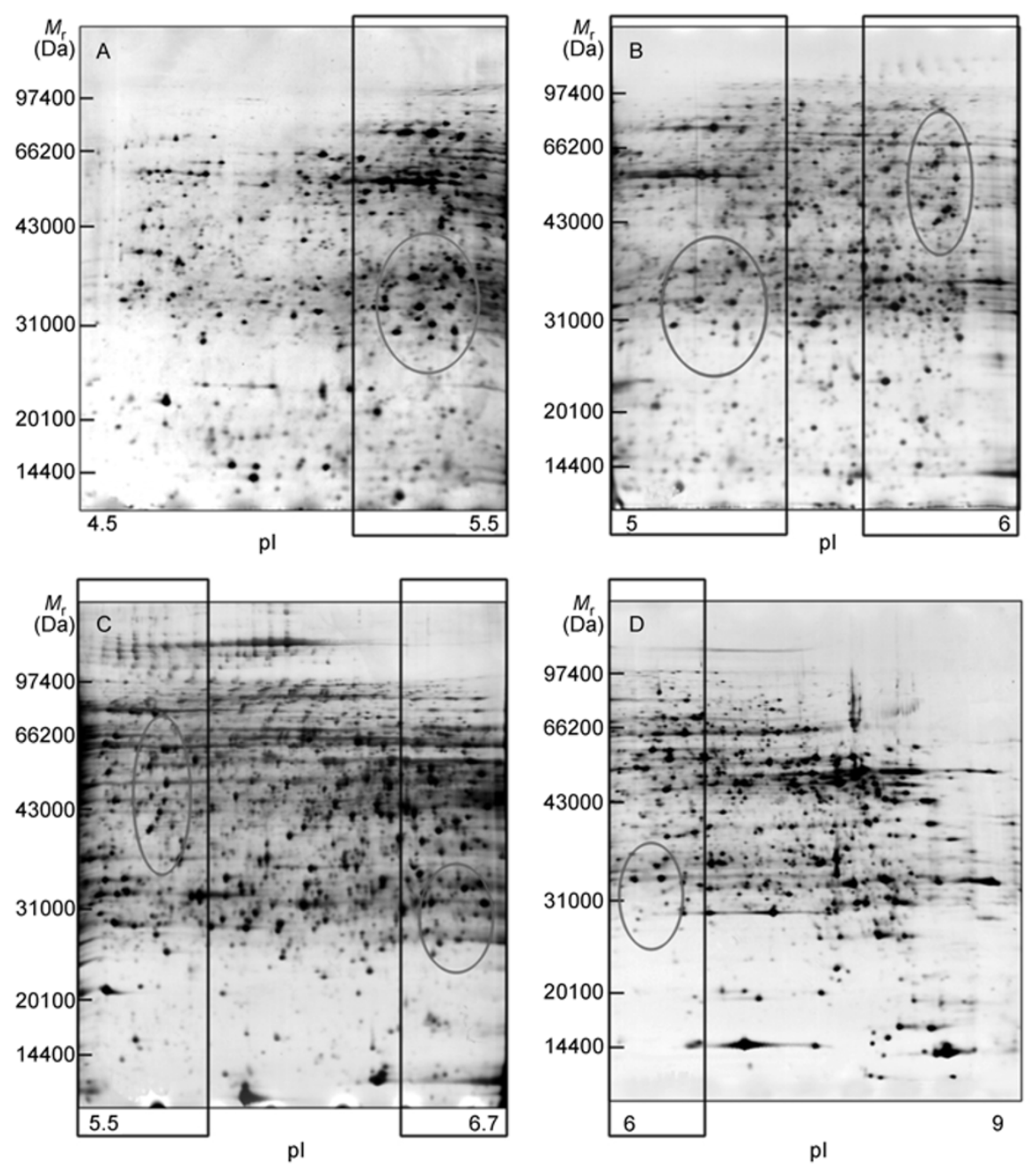

Figure 2 Analytical silver-stained gels with $90 \mu \mathrm{g}$ human liver protein. A, IPG pH 4.5-5.5; B, IPG pH 5-6; C, IPG pH 5.5-6.7; D, IPG pH 6-9. Overlapping regions and overlapping proteins are indicted by red circles.

reversed electroosmotic flow and increasing flexibility of the gel matrix [21]. In the present study, we modified the rehydration buffer by adding 15\% 2-propanol and 5\% glycerol and this resulted in better-resolved 2-D gels (Figure 3B) compared with the gels on which unmodified rehydration buffer (Figure 3A) was used. Figure 3C distinctly shows horizontal streaking, particularly at the basic end, which might be caused by the depletion of DTT in the buffer during IEF. By increasing the amount of DTT (from $0.2 \%$ to $2.5 \%$ ) and IPG buffer (from $0.5 \%$ to $2 \%$ ) in the rehydration buffer, the streaking was diminished (Figure 3D). To avoid streaking, hydroxyethyl disulfide (HED) reagent (DeStreak, Amersham Biosciences) has been used instead of DTT [22]. HED forms mixed disulfides, thus protecting the active cysteine thiol-groups from uncontrolled modifications. Olsson et al. [22] were the first to demonstrate the elimination of streaking, the simplification of spot patterns and the improvement of reproducibility on 2-D gels when focusing was done in the presence of HED. In this study, we have used $1.2 \%$ HED in the rehydration buffer.

In principle, focusing time optimization is necessary for optimum 2-D quality and reproducibility [23]. We followed the IEF protocol of Gorg et al. [3] for in-gel rehydration sample application, and the IEF protocol described in Table 1 for cup loading. The final parameter for cup loading is a sample-loading step with $200 \mathrm{~V}$ for $10 \mathrm{~min}$ and $600 \mathrm{~V}$ for $20 \mathrm{~min}$, a sample entry step following a gradient from 600 to $4000 \mathrm{~V}$ and a final focusing step of $8000 \mathrm{~V}$ for $8 \mathrm{~h}$. For preparative samples, the final focusing time was prolonged.

In summary, the conditions for optimal separation of alkaline proteins were that the proteins were rehydrated with the modified rehydration buffer $\left(7 \mathrm{~mol} \mathrm{~L}^{-1}\right.$ urea, $2 \mathrm{~mol} \mathrm{~L}^{-1}$ thiourea, 4\% CHAPS, 5\% glycerol, 15\% 2-propanol, $1.2 \%$ DeStreak reagent, 2.5\% DTT, 2\% IPG buffer 6-11), samples were applied by cup loading and focused following the IEF protocol in Table 1. We used these conditions for analytical gels (Figure 2D) and preparative gels (Figure 4D) in the $\mathrm{pH}$ range of $6-9$. 


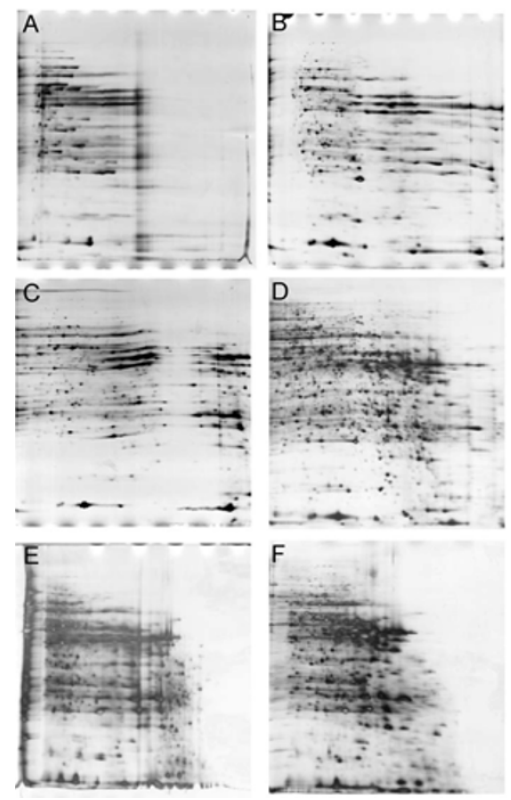

Figure 3 Progressively improved resolution of alkaline $\mathrm{pH}$ range 2-DE gels. Human liver protein extracts were resolved on IPG strips $\mathrm{pH}$ 6-9 (A-D) or $\mathrm{pH}$ 6-11 (E and F) with cup-loading. A, Ordinary rehydration buffer. B, Modified rehydration buffer with $15 \%$ 2-propanol and 5\% glycerol. C, Modified rehydration buffer with $0.2 \%$ DTT and $0.5 \%$ IPG buffer. D, Modified rehydration buffer with $2.5 \%$ DTT and $2 \%$ IPG buffer. E, $2.5 \%$ DTT in the IPG strip pH 6-11 rehydration buffer. F, $1.2 \%$ hydroxyethyl disulfide (DeStreak) was replaced.

\subsection{Protein spot identification on the reference map}

For the identification of proteins by MALDI TOF-TOF, the peptide mixtures were spotted onto the target plate and air-dried. This operation was repeated several times, and then the spots were covered with a saturated solution of CHCA. This sample loading technique was effective for desalting and concentrating the peptide mixture prior to MALDI analysis and produced clean and sharp signals comparable to those obtained by conventional sample application in which the mixture of peptides and CHCA solution are directly applied onto the target [24]. The MALDI TOF-TOF MS was calibrated with external and internal standards. Internal calibration was performed using two autolysis peaks of trypsin in the tryptic peptide mixture, which made the samples and calibrates relative to each other anywhere, and provided enhanced mass accuracy (better than $0.001 \%$ ) during the high-throughput protein identification. For data analysis, a database composed of IPI version 3.07 and its reverse database was built. For protein identification, only the protein at the top of the list (rank 1) in each spot was selected. If the rank 1 protein was coded by a sequence in the reverse database, then the identified protein for this spot was treated as a false result and deleted.

Some of the identified proteins are labeled on the $\mathrm{pH} 4-7$ (Figure 4A), pH 5-6 (Figure 4B), pH 5.5-6.7 (Figure 4C),
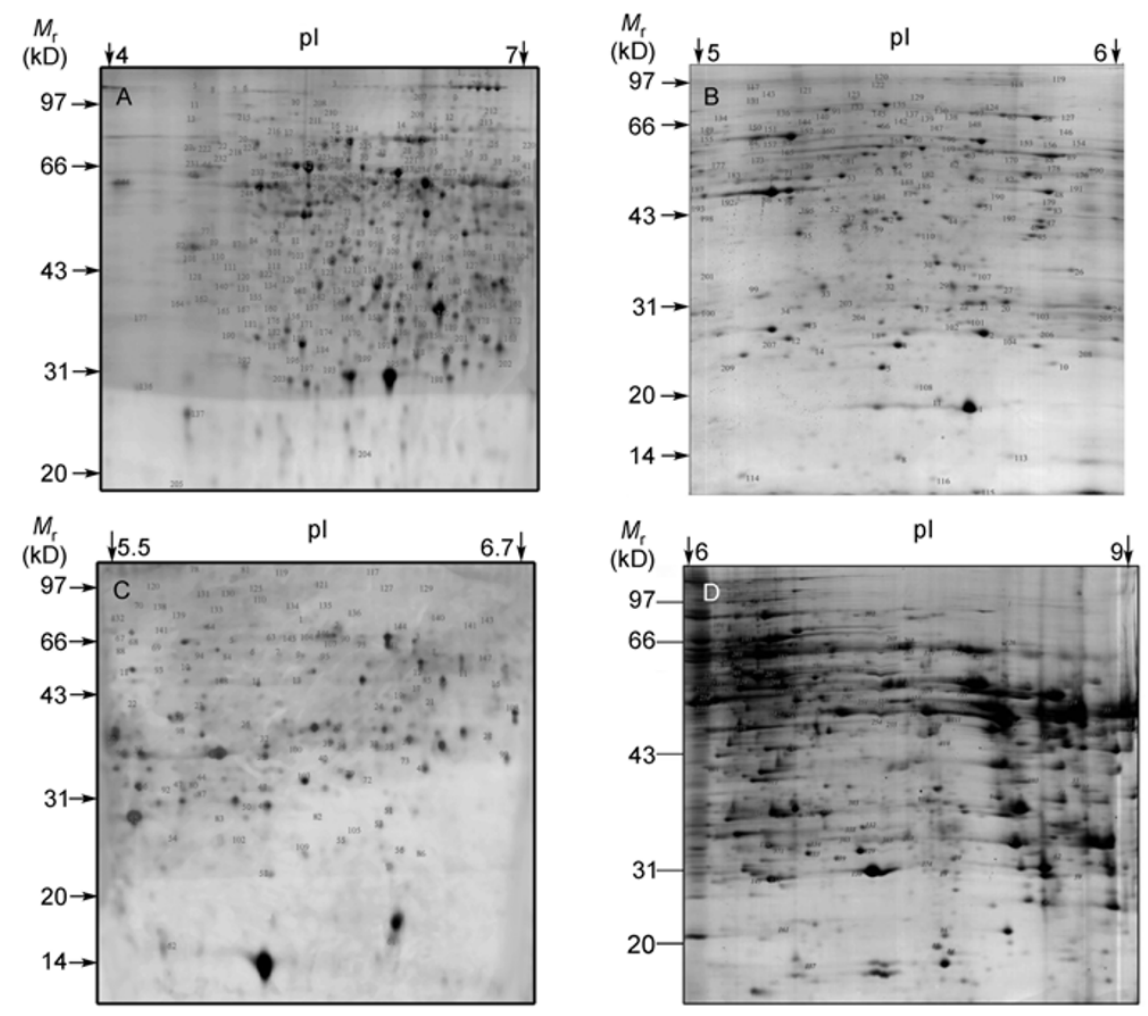

Figure 4 Identified proteins labeled on the pH 4-7 2-DE gel (A), pH 5-6 2-DE gel (B), pH 5.5-6.7 2-DE gel (C) and pH 6-9 2-DE gel (D). The numbers match the position of the identified protein in the corresponding Appendix Tables S1-S4 in the electronic version. 
and pH 6-9 (Figure 4D) 2-DE gels and annotated in Table 2 (see Appendix Tables S1-S4 in the electronic version for details). In all, 1000 spots were excised from the gels and digested and 786 proteins were successfully identified by MALDI-TOF-TOF mass spectrometry. Most of the hydrophobicity values for the proteins range from -0.6 to 0 , indicating that most of the identified proteins are hydrophilic (Figure 5A). The number of identified proteins that are extremely hydrophobic (values $>0.4$ ) is low. From Figure 5B, we conclude that the molecular weight of most of the identified proteins is between 10 and $60 \mathrm{kD}$. Proteins of more than $100 \mathrm{kD}$ are relatively rare. The $\mathrm{pI}$ values in Figure 5C indicate that close to $50 \%$ of the identified proteins have pIs in the alkaline $(\mathrm{pH} 8-11)$ range. These results show the effective separation of the alkaline range proteins using ul- tra-zoom gels. Proteins with pIs in the extreme alkaline $(>9)$ or acid $(<4)$ ranges are relatively rare compared with those in the middle $\mathrm{pH}$ range.

We used the gene ontology to classify the identified proteins (Figure 6). We found that $72.2 \%$ can be annotated to biological processes, $57.4 \%$ can be annotated to cellular components and $81.7 \%$ can be annotated to molecular functions. Thus less than $20 \%$ of the identified proteins could not be annotated indicating that they may have functions that are yet to be recognized in biological systems. The biological process classification (Figure 6A) revealed that the per- centage of proteins involved in carbohydrate, lipid or protein metabolism is relatively high at $11.90 \%, 9.90 \%$ and $20.50 \%$, respectively, consistent with the important functions of the human liver. Other biological processes repre-
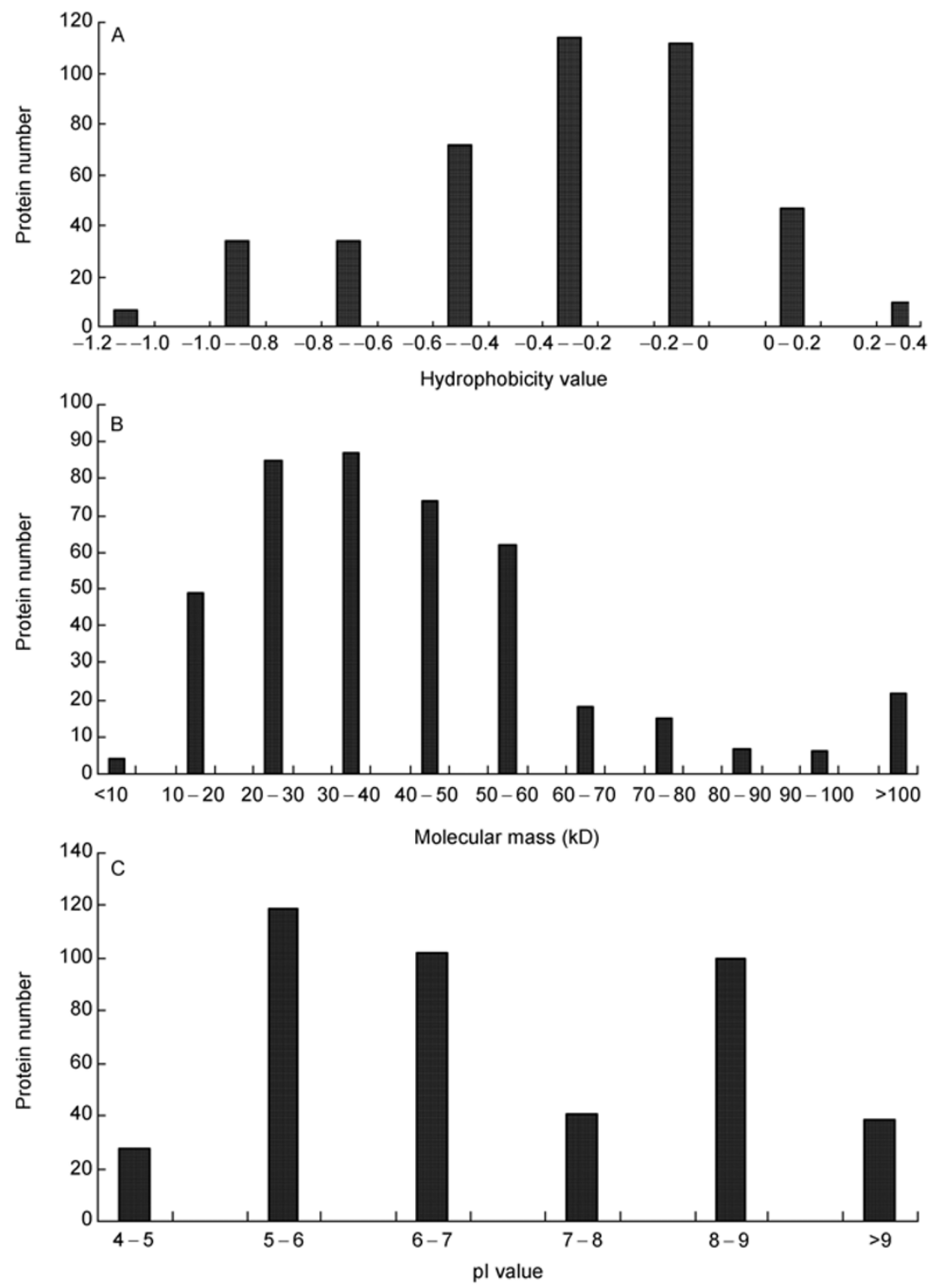

Figure 5 Distribution of the hydrophobicity values (A), molecular weights (B) and pI values (C) of the identified proteins. 

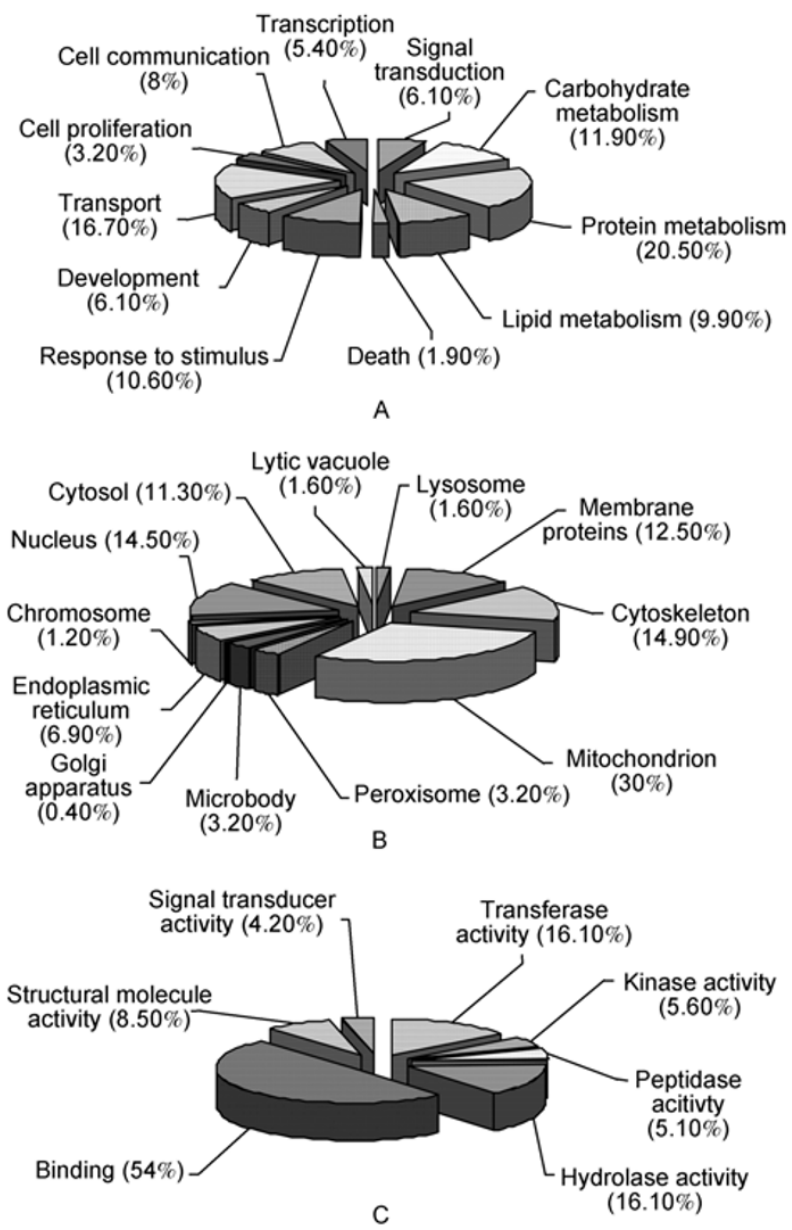

Figure 6 Gene Ontology classification of the identified proteins by the biological process (A), subcellular location (B), and molecular function (C).

sented are signal transduction $(6.10 \%)$, cell communication $(8 \%)$, development $(6.10 \%)$, and response to stimulus $(10.60 \%)$. Analysis of the subcellular location ontology (Figure 6B) shows that $12.50 \%$ of the identified proteins were classified as membrane proteins, indicating that the methods of sample preparation effectively separated hydrophobic membrane proteins. Other well-represented subcellular locations for the identified proteins are the nucleus (about 15\%), the endoplasmic reticulum (6.90\%), microbodies $(3.20 \%)$, and the mitochondria (30\%). Classification of the identified proteins by molecular function revealed that at $54 \%$, binding was the dominant function (Figure 6C). Binding proteins may be widely used in the processes such as transportation, catalysis, and metabolism. Other molecular functions assigned to the identified proteins were structural molecule activity $(8.50 \%)$, signal transducer $(4.20 \%)$, transferase $(16.10 \%)$, kinase activity $(5.60 \%)$ and hydrolase $(16.10 \%)$.

Along with metabolism, another important function of the liver is the removal of potentially harmful or toxic substances from the body. Ammonia, an extremely toxic base, is formed in the metabolism of proteins and its accumula- tion in the body would quickly be fatal. The liver contains a system of carrier molecules and enzymes that quickly convert ammonia (and carbon dioxide) into urea. Carbamoyl-phosphate synthase, an initial enzyme in the urea synthesis system, is one of the proteins that we identified among the annotated proteins.

\subsection{Protein heterogeneity}

Protein heterogeneity occurs when multiple spots represent one protein on a 2-DE map with migration to different $M_{\mathrm{r}}$ and/or pI, and could be the result of posttranslational modification such as phosphorylation, glycosylation or acetylation, the formation of dimers, binding to other protein molecules, or proteolysis [25-27]. Modified proteins have been estimated to make up more than $25 \%$ of the total number of spots on a 2-D gel [28]. In the present study, we successfully identified 786 protein spots representing 432 unique proteins, indicating that many proteins are represented by multiple spots. For example, on the $\mathrm{pH} 4-72-\mathrm{DE}$ map (Figure 4A) protein spots numbered 80, 83, 85 and 89 were all identified as acyl-dehydrogenase, and the spots numbered 146, 151 and 152, all identified as retinal dehydrogenase 1, migrate to a similar $M_{\mathrm{r}}$ but have different $\mathrm{pI}$. The spots numbered 181, 182, 190, 195 and 196, identified as stress-70 protein, and the spots numbered 97, 116, 168, 171 and 172 , identified as $60 \mathrm{kD}$ heat shock protein, have different $M_{\mathrm{r}}$ and $\mathrm{pI}$ (Figure 4A).

\section{Conclusion}

In the present study, we performed proteomic analysis of normal human livers using ultra-zoom gels. We obtained a high resolution profile from 2-DE gels and constructed a 2-DE reference map of normal human liver from $\mathrm{pH} 4.5$ to $\mathrm{pH} 9$ with the detection of 5481 protein spots. The isoelectric focusing protocol for the alkaline $\mathrm{pH}$ range was optimized. All identified proteins were bioinformatically annotated according to their biological process, subcellular location, and molecular function using the Gene Ontology. Our composite 2-DE reference map provides a valuable resource for comparative proteomic analyses of normal and pathologic human livers.

This work was supported by the National Natural Science Foundation of China (Grant Nos. 30621063, 20635010 and 20735005), the National Key Basic Research Program of China (Grant Nos. 2006CB910801, 2004CB518707 and 2007CB914100) and the National High Technology Research and Development Program of China (Grant Nos. 2006AA02A308 and 2008AA02Z309).

1 Jia H, Louet S. China pushes liver proteomics. Nat Biotechnol, 2004, 22: 136

2 He F. Human liver proteome project: Plan, progress, and perspectives. Mol Cell Proteomics, 2005, 4: 1841-1848 
3 Washburn M P, Wolters D, Yates J R. Large-scale analysis of the yeast proteome by multidimensional protein identification technology. Nat Biotechnol, 2001, 19: 242-247

4 Gorg A, Obermaier C, Boguth G, et al. The current state of two-dimensional electrophoresis with immobilized $\mathrm{pH}$ gradients. Electrophoresis, 2000, 21: 1037-1053

5 Aebersold R, Mann M. Mass spectrometry-based proteomics. Nature, 2003, 422: 198-207

6 Mann M, Jensen O N. Proteomic analysis of post-translational modifications. Nat Biotechnol, 2003, 21: 255-261

7 Packer N H, Ball M S, Devine P L. Glycoprotein detection of 2-D separated proteins. Methods Mol Biol, 1999, 112: 341-352

8 Wildgruber R, Harder A, Obermaier C, et al. Towards higher resolution: Two-dimensional electrophoresis of Saccharomyces cerevisiae proteins using overlapping narrow immobilized $\mathrm{pH}$ gradients. Electrophoresis, 2000, 21: 2610-2616

9 Westbrook J A, Yan J X, Wait R, et al. Zooming-in on the proteome: Very narrow-range immobilised $\mathrm{pH}$ gradients reveal more protein species and isoforms. Electrophoresis, 2001, 22: 2865-2871

10 Gorg A, Postel W, Weser J, et al. Improved resolution of PI (alpha 1-antitrypsin) phenotypes by a large-scale immobilized $\mathrm{pH}$ gradient. Am J Hum Genet, 1985, 37: 922-930

11 Candiano G, Bruschi M, Musante L, et al. Blue silver: A very sensitive colloidal Coomassie G-250 staining for proteome analysis. Electrophoresis, 2004, 25: 1327-1333

12 Harder A, Wildgruber R, Nawrocki A, et al. Comparison of yeast cell protein solubilization procedures for two-dimensional electrophoresis. Electrophoresis, 1999, 20: 826-829

13 Boucherie H, Dujardin G, Kermorgant M, et al. Two-dimensional protein map of Saccharomyces cerevisiae: construction of a geneprotein index. Yeast, 1995, 11: 601-613

14 Shaw M M, Riederer B M. Sample preparation for two-dimensional gel electrophoresis. Proteomics, 2003, 3: 1408-1417

15 Langen $\mathrm{H}$, Berndt $\mathrm{P}$, Roder D, et al. Two-dimensional map of human brain proteins. Electrophoresis, 1999, 20: 907-916

16 Herbert B R, Harry J L, Packer N H, et al. What place for polyacrylamide in proteomics? Trends Biotechnol, 2001, 19: S3-9

17 Medjahed D, Smythers G W, Powell D A, et al. VIRTUAL2D: A web-accessible predictive database for proteomics analysis. Proteomics, 2003, 3: 129-138

18 Sanchez J C, Rouge V, Pisteur M, et al. Improved and simplified in-gel sample application using reswelling of dry immobilized $\mathrm{pH}$ gradients. Electrophoresis, 1997, 18: 324-327

19 Li X M, Patel B B, Blagoi E L, et al. Analyzing alkaline proteins in human colon crypt proteome. J Proteome Res, 2004, 3: 821-833

20 Wildgruber R, Reil G, Drews O, et al. Web-based two-dimensional database of Saccharomyces cerevisiae proteins using immobilized $\mathrm{pH}$ gradients from $\mathrm{pH} 6$ to $\mathrm{pH} 12$ and matrix-assisted laser desorption/ionizationtime of flight mass spectrometry. Proteomics, 2002, 2: 727-732

21 Hoving S, Gerrits B, Voshol H, et al. Preparative two-dimensional gel electrophoresis at alkaline $\mathrm{pH}$ using narrow range immobilized pH gradients. Proteomics, 2002, 2: 127-134

22 Olsson I, Larsson K, Palmgren R, et al. Organic disulfides as a means to generate streak-free two-dimensional maps with narrow range basic immobilized $\mathrm{pH}$ gradient strips as first dimension. Proteomics, 2002, 2: 1630-1632

23 Gorg A, Obermaier C, Boguth G, et al. Recent developments in two-dimensional gel electrophoresis with immobilized $\mathrm{pH}$ gradients: Wide $\mathrm{pH}$ gradients up to $\mathrm{pH} 12$, longer separation distances and simplified procedures. Electrophoresis, 1999, 20: 712-717

24 Padliya N D, Wood T D. A strategy to improve peptide mass fingerprinting matches through the optimization of matrix-assisted laser desorption/ionization matrix selection and formulation. Proteomics, 2004, 4: 466-473

25 Li Z B, Lehar M, Braga N, et al. Study of human laryngeal muscle protein using two-dimensional electrophoresis and mass spectrometry. Proteomics, 2003, 3: 1325-1334

26 Zhan X, Desiderio D M. A reference map of a human pituitary adenoma proteome. Proteomics, 2003, 3: 699-713

27 Jones A, Faldas A, Foucher A, et al. Visualisation and analysis of proteomic data from the procyclic form of Trypanosoma brucei. Proteomics, 2006, 6: 259-267

28 Celis J E, Rasmussen H H, Gromov P, et al. The human keratinocyte two-dimensional gel protein database (update 1995): Mapping components of signal transduction pathways. Electrophoresis, 1995, 16: 2177-2240

Open Access This article is distributed under the terms of the Creative Commons Attribution License which permits any use, distribution, and reproduction in any medium, provided the original author(s) and source are credited. 